\title{
Metformin reduces glycometabolism of papillary thyroid carcinoma in vitro and in vivo
}

\author{
Chen-Tian Shen1,2,*, Wei-Jun Wei1,*, Zhong-Ling Qiu1, Hong-Jun Song1, \\ Xin-Yun Zhang', Zhen-Kui Sun' ${ }^{1}$ and Quan-Yong Luo' \\ 'Department of Nuclear Medicine, Shanghai Jiao Tong University Affiliated Sixth People's Hospital, \\ Shanghai, People's Republic of China \\ 2Shanghai Jiao Tong University School of Medicine, Shanghai, People's Republic of China \\ *(C-T Shen and W-J Wei contributed equally to this work)
}

Correspondence should be addressed to Q-Y Luo

Email

lqyn@sh163.net

\begin{abstract}
More aggressive thyroid cancer cells show a higher activity of glycometabolism. Targeting cancer cell metabolism has emerged as a novel approach to prevent or treat malignant tumors. Glucose metabolism regulation effect of metformin in papillary thyroid cancer was investigated in the current study. Human papillary thyroid carcinoma (PTC) cell lines BCPAP and KTC1 were used. Cell viability was detected by CCK 8 assay. Glucose uptake and relative gene expression were measured in metformin (0-10 $\mathrm{mM}$ for $48 \mathrm{~h}$ )-treated cells by ${ }^{18 F-F D G ~ u p t a k e ~ a s s a y ~ a n d ~ w e s t e r n ~ b l o t t i n g ~ a n a l y s i s, ~ r e s p e c t i v e l y . ~ M i c r o P E T / ~}$ $\mathrm{CT}$ imaging was performed to detect $18 \mathrm{~F}-\mathrm{FDG}$ uptake in vivo. After treatment with metformin at $0,2.5,5$ and $10 \mathrm{mM}$ for $48 \mathrm{~h}$, the ratio of $\mathrm{p}$-AMPK to total AMPK showed significant rising in a dose-dependent manner in both BCPAP and KTC1, whereas $\mathrm{p}$-AKT and p-mTOR expression level were downregulated. ${ }^{18} \mathrm{~F}-\mathrm{FDG}$ uptake reduced after metformin treatment in a dose-dependent manner, corresponding to the reduced expression level of HK2 and GLUT1 in vitro. Xenograft model of PTC using BCPAP cells was achieved successfully. MicroPET/CT imaging showed that in vivo ${ }^{18} \mathrm{~F}-\mathrm{FDG}$ uptake decreased after treatment with metformin. Immunohistochemistry staining further confirmed the reduction of HK2 and GLUT1 expression in the tumor tissue of metformintreated PTC xenograft model. In conclusion, metformin could reduce glucose metabolism of PTC in vitro and in vivo. Metformin, by targeting glycometabolism of cancer cells, could be a promising adjuvant therapy alternative in the treatment modality of advanced thyroid carcinoma.
\end{abstract}

\section{Key Words \\ - metformin \\ - glucose metabolism \\ - papillary thyroid carcinoma \\ - 18F-FDG uptake}

Journal of Molecular Endocrinology

(2017) 58, 15-23

\section{Introduction}

Thyroid cancer is increasing globally, especially in young women and differentiated thyroid cancer (DTC) is the most predominant type (Chen et al. 2016, Siegel et al. 2016). Clinically, it has been widely accepted that 18 F-fluoro-2deoxy-D-glucose (18F-FDG) uptake in metastatic lesions of DTC could provide valuable prognostic information. Metastatic lesions with high ${ }^{18}$ F-FDG uptake have more dedifferentiated, aggressive and metabolically active tumor cells, thereby indicating a poor prognosis. Conversely, a negative 18F-FDG PET/CT imaging predicts 
a more favorable prognosis even in patients with positive radioiodine whole body scan (Masson-Deshayes et al. 2015, Pryma et al. 2006, Salvatori et al. 2015). In molecular level, overexpression of glucose transporter-1 (GLUT1) on the cell membrane of thyroid cancer could contribute to this phenomenon (Schonberger et al. 2002).

Metformin (N,N-dimethylbiguanide), an oral biguanide drug with well-established efficacy and safety profiles, is commonly prescribed as the first-line treatment for patients with type 2 diabetes mellitus (T2DM). Generally, this drug improves blood glucose control and insulin sensitivity by reducing hepatic glucose production, gluconeogenesis and intestinal glucose absorption as well as increasing peripheral glucose uptake (Crandall et al. 2008). Recently, its anti-tumor activity has been widely investigated. There are more than 250 registered clinical trials in patients with breast, ovarian, lung, colorectal and pancreatic cancers using metformin alone or in combination with other therapies (ClinicalTrials.gov). Although popularly studied, the exact effect of metformin on thyroid cancer is still controversial.

Experimental studies have demonstrated that metformin could inhibit cell proliferation and promote apoptosis in multiple thyroid cancer cell lines through adenosine monophosphate-activated protein kinase (AMPK) activation, mammalian target of rapamycin (mTOR) signaling inhibition and cell cycle arrest (Chen et al. 2012, Cho et al. 2014a,b, Hanly et al. 2015). Epidemiological studies have showed that the use of metformin was linked to a decreased risk of thyroid cancer in T2DM patients and a higher remission rate in T2DM patients with thyroid cancer (Klubo-Gwiezdzinska et al. 2013, Tseng 2014). However, meta-analyses have indicated that metformin-induced reduction of cancer incidence and mortality seemed to be of modest magnitude and not affecting all populations equally (Gandini et al. 2014). And more recently, an observational study demonstrated that neither use of metformin nor of any other antidiabetic drugs was associated with a decreased risk of thyroid cancer (Becker et al. 2015). However, the total number of metformin-used thyroid cancer patients in this study was much small.

Targeting cancer cell metabolism has emerged as a novel approach to prevent or treat cancers and one of the primary metabolic changes observed in malignant cell transformation is an increased catabolic glucose metabolism (Pollak 2012, Vander Heiden 2011). Anticancer effects of metformin in proliferation and apoptosis of thyroid cancer have been frequently studied. However, few studies have reported the effect of metformin on the glucose metabolism in thyroid cancer. Based on this, we focused on the glycometabolism regulation effect of metformin in thyroid cancer in vitro and in vivo in the current study.

\section{Materials and methods}

\section{Cell culture}

Human papillary thyroid carcinoma cell lines BCPAP (DSMZ, German Collection of Microorganisms and Cell Cultures) and KTC1 (kindly provided by Stem Cell Bank, Chinese Academy of Sciences, Shanghai, China) were cultured in RPMI-1640 supplemented with 10\% fetal bovine serum, $100 \mathrm{U} / \mathrm{mL}$ penicillin, $100 \mu \mathrm{g} / \mathrm{mL}$ streptomycin and $1 \%$ nonessential amino acids (100x) (Gibco). All the cells were incubated at $37^{\circ} \mathrm{C}$ in a humidified chamber supplemented with $5 \% \mathrm{CO}_{2}$.

\section{Cell viability assay}

Cells $\left(1 \times 10^{4}\right.$ cells/well) were seeded in 96-well plates. After culturing for $24 \mathrm{~h}$, cells were rinsed with phosphate-buffered saline (PBS) and treated with metformin (MP Biomedicals, Santa Ana, CA, USA) at various concentrations (0-50 mM) for $48 \mathrm{~h}$. Cell viability was then evaluated using a CCK8 (Cell Counting kit-8) kit according to the manufacturer's protocol. Briefly, $10 \mu \mathrm{L}$ CCK8 solution (YEASEN, Shanghai, China) was added to each well, and the samples were incubated at $37^{\circ} \mathrm{C}$ for $2 \mathrm{~h}$ before the absorbance was measured at $450 \mathrm{~nm}$ wave length. Each experimental condition, including blank wells, control wells and wells treated with metformin, was assayed in duplicate, and all experiments were performed at least three times.

\section{In vitro ${ }^{18} \mathrm{~F}-\mathrm{FDG}$ uptake assay}

For ${ }^{18} \mathrm{~F}-\mathrm{FDG}$ uptake measurement, cells were seeded in 6 -well plates $\left(5 \times 10^{5}\right.$ cells per well $)$ overnight, and then subsequently treated with metformin at $0,2.5,5$ and $10 \mathrm{mM}$ for $48 \mathrm{~h}$. Later, the cell culture medium was changed by sugar-free RPMI- 1640 culture medium. After $6 \mathrm{~h}$, cells were incubated with ${ }^{18}$ F-FDG (Atomic firm Sinovac Pharmaceutical Co., LTD., Shanghai, China) at a final concentration of $37 \mathrm{kBq} / \mathrm{mL}$. After 60 -min incubation, cells were washed twice with cold phosphate-buffered saline (PBS) and lysed with $0.1 \mathrm{M} \mathrm{NaOH}$. Radioactivity was measured using a gamma counter (Capintec, Inc., USA) and expressed as \% uptake per well relative to controls. Experiments were repeated for three times.

Published by Bioscientifica Ltd 


\section{Western blotting analysis}

Cells were seeded in 6-well plates at a density of $1 \times 10^{6}$ cells/well. After relevant treatment, cells were harvested in RIPA lysis buffer containing proteinase and phosphatase inhibitors (Beyotime, Nantong, Jiangsu, China). Protein was quantified using a BCA protein assay kit (Beyotime). Equal amounts of cell lysates were separated by 6-10\% SDS-PAGE and electrophoretically transferred to PVDF membrane. The membrane was then blocked and probed with primary antibodies (anti-AMPK, anti-phospho-AMPK, anti-GLUT1, anti-HK2, anti-AKT, anti-phospho-AKT, anti-mTOR, anti-phospho-mTOR and anti- $\beta$-actin; $1: 1000$ ) followed by HRP (horseradish peroxidase)-labeled goat anti-mouse IgG or HRP-labeled goat anti-rabbit IgG (1:5000). Chemiluminescence was used to analyze protein levels, and $\beta$-actin was used as a protein loading control. All antibodies used in this study were purchased from Proteintech Group, Inc., Rosemont, IL, USA. Semi-quantitative analysis was conducted using ImageJ 1.49v (NIH, Bethesda, MD, USA). Experiments were repeated for three times.

\section{Immunohistochemistry (IHC)}

Paraffin-embedded tissues from xenograft tumor were cut into $3 \mu \mathrm{m}$ sections. Endogenous peroxidase activity was blocked with $3 \% \mathrm{H}_{2} \mathrm{O}_{2}$ for $15 \mathrm{~min}$. Antigen retrieval was performed by boiling the sections for $10 \mathrm{~min}$ in citrate buffer ( $\mathrm{pH}$ 6.0) and cooling at room temperature, followed by blocking with 10\% normal goat serum for $1 \mathrm{~h}$. After incubation with primary antibody (anti-GLUT1 and anti-HK2; 1:100) overnight at $4^{\circ} \mathrm{C}$, the sections were incubated with horseradish peroxidase- (HRP-) conjugated anti-mouse/rat secondary antibodies. After washing with PBS three times for $5.0 \mathrm{~min}$ each time, peroxidase substrate DAB kit was used for visualization according to the manufacturer's instructions. Semi-quantitative analysis was performed by digital image analysis with the Image-Pro Plus 6.0 software (Media Cybernetics, Rockville, MD, USA).

\section{Xenograft model}

Animal studies were carried out in compliance with the guideline on Administration of Lab Animals (Ministry of Science and Technology of China) and approved by the Ethics Committee of Shanghai Jiao Tong University Affiliated Sixth People's Hospital. For PTC xenograft implantation, a total of $2 \times 10^{7}$ cells were subcutaneously injected into the left forelimb of 6-week-old female
BALB/c-nu mice. The animals were kept in individual ventilated cages in compliance with institutional guidelines.

\section{MicroPET/CT imaging and analysis}

MicroPET/CT scans and image analysis were performed using a Super Nova MicroPET/CT (Pingseng Healthcare (KunShan), Inc., Kunshan, Jiangsu, China). Water and food were not supplied until 18 F-FDG injection at least for 8 h. Each tumor-bearing mouse was injected with 4.959$4.958 \mathrm{MBq}(107-134 \mu \mathrm{Ci})$ of ${ }^{18} \mathrm{~F}-\mathrm{FDG}$ (Atomic firm Sinovac Pharmaceutical Co., LTD., Shanghai) in $200 \mu \mathrm{L}$ of saline via tail vein. Twelve-minute static scans were acquired at $1 \mathrm{~h}$ after injection, and animals were maintained under $2 \%$ isoflurane anesthesia during scanning period. Body temperature was maintained using a heating pad provided with the small-animal PET/CT system. For semi-quantitative analysis, 3-dimensional regions of interest (ROIs) were carefully delineated over the borders of the tumor ( $\mathrm{T}$ ) and a part of the liver as a non-target (NT) reference. ${ }^{18}$ F-FDG uptake was acquired as SUVmax automatically after delineating the ROIs. The SUVmax ratio (T/NT) was calculated and compared between groups.

\section{Statistics analysis}

Analyses were performed using the Statistical Package for the Social Sciences, version 20.0 (SPSS) and GraphPad prism version 5.0 (GraphPad Software). All group data are expressed as means \pm standard deviation (s.D.). Student's t-test was performed to compare means of different groups. All $P$ values are two-tailed. $P<0.05$ was considered as a statistically significant difference.

\section{Results}

\section{Cell viability inhibition in vitro}

To determine the effect of metformin on the viability of thyroid cancer cell, we performed CCK8 assay. Two PTC cell lines, KTC1 and BCPAP, were treated with metformin at various concentrations $(0,10,20,30,40$ and $50 \mathrm{mM})$ for $48 \mathrm{~h}$. The results demonstrated that after treatment with metformin, all thyroid cancer cell lines showed dosedependent decreases in cell viabilities (Fig. 1).

\section{AMPK activation}

To confirm metformin-mediated AMPK activation through AMPK phosphorylation in PTC cell lines, proteins from

Published by Bioscientifica Ltd 

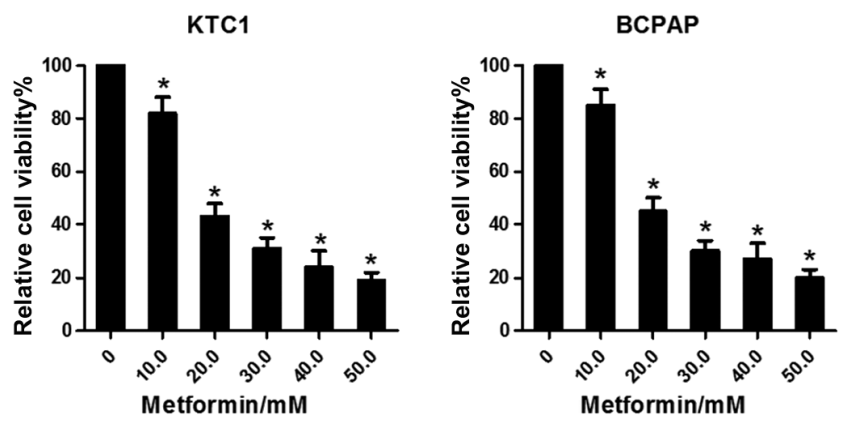

Figure 1

Effects of metformin on cell viability in human papillary thyroid cancer cells. ${ }^{*} P<0.05$.

metformin-treated cells (KTC1 and BCPAP) at 0, 2.5, 5 and $10 \mathrm{mM}$ for $48 \mathrm{~h}$ were harvested and the expression of AMPK and p-AMPK was measured by western blotting. As can be seen in Fig. 2, the ratio of p-AMPK to total AMPK showed a significant rise in a dose-dependent manner in both KTC1 and BCPAP.

\section{F-FDG uptake in vitro}

${ }^{18} \mathrm{~F}-\mathrm{FDG}$ enters cell via the same facilitative transporters of glucose. It is then phosphorylated and trapped in the cytoplasm. So glucose consumption can be detected and visualized non-invasively by using ${ }^{18} \mathrm{~F}-\mathrm{FDG}$. As showed in Fig. 3(A and B), after treatment with metformin at $0,2.5$,
A

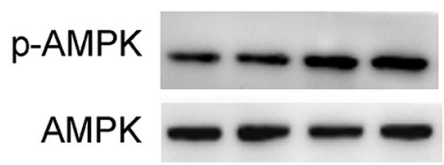

C

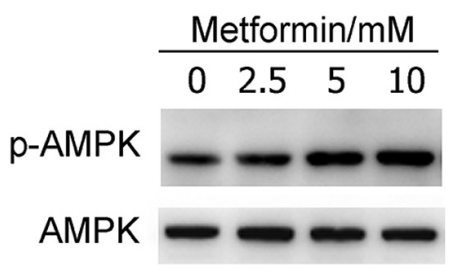

\begin{tabular}{|c|}
\hline Metformin/mM \\
\hline $\begin{array}{llll}0 & 2.5 & 5 & 10\end{array}$ \\
\hline
\end{tabular}
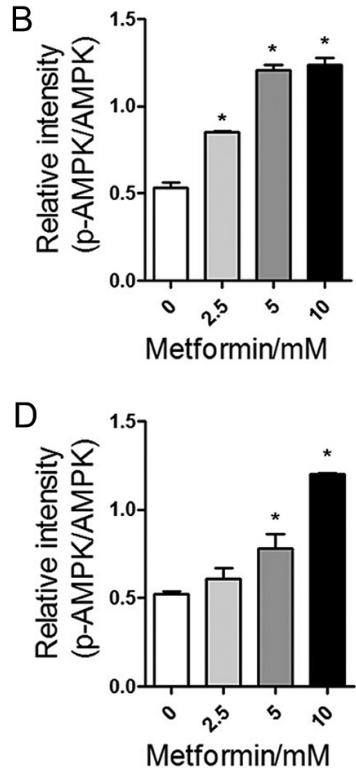

Figure 2

Western blotting analysis of AMPK and p-AMPK in metformin-treated cells at different concentrations. (A) KTC1; (C) BCPAP; (B) and (D), semi-quantitative analysis of blots in $(A)$ and $(C)$, respectively. ${ }^{*} P<0.05$.
5 and $10 \mathrm{mM}$ for $48 \mathrm{~h}$, PTC cells showed a dose-dependent reduction of ${ }^{18} \mathrm{~F}-\mathrm{FDG}$ uptake.

\section{Decreased expression of GLUT1 and HK2 in vitro}

Glucose transporter-1 (GLUT1) and hexokinase-2 (HK2) are among the major proteins regulating transportation and transformation of glucose, respectively. Their expression level and function status are of great significance in the glucose metabolism in cancer cells (Colell et al. 2007, Mondal et al. 2015). Proteins from metformin-treated cells (KTC1 and BCPAP) at 0, 2.5, 5 and $10 \mathrm{mM}$ for $48 \mathrm{~h}$ were harvested, and the expression of HK2 and GLUT1 was measured by western blotting. The results demonstrated that HK2 and GLUT1 in the two PTC cell lines showed dose-dependent decreases (Fig. 3C, D, E and F).

\section{AKT/mTOR signaling suppression}

AKT/mTOR pathway is an essential signaling cascade that interacts with glucose metabolism in cancer cells (Robey $\&$ Hay 2009). Proteins from metformin $(0,2.5,5$ and $10 \mathrm{mM}$ for $48 \mathrm{~h}$ ) -treated PTC cells (KTC1 and BCPAP) were harvested, and the expression level of AKT, p-AKT, mTOR and p-mTOR was measured by western blotting. The results demonstrated that after treatment with metformin, p-AKT and p-mTOR were significantly decreased in PTC cell lines (Fig. 4).

\section{In vivo ${ }^{18} \mathrm{~F}-\mathrm{FDG}$ microPET/CT imaging}

Based on the above evidence, ${ }^{18} \mathrm{~F}-\mathrm{FDG}$ microPET/CT imaging was performed to further confirm the effects of metformin on glucose metabolism of PTC in vivo. Xenograft model of PTC using BCPAP cells was successfully achieved. After 2 weeks, two groups (A and B) were randomly divided with 6 mice per group. Metformin $(300 \mathrm{mg} / \mathrm{kg}, \mathrm{IP}, \mathrm{QD})$ treatment was done for one week in group A (metformin/+), whereas same volume of saline was intraperitoneally injected as control in group B (metformin/-). After three weeks of cells injection, in vivo ${ }^{18 F-F D G ~ m i c r o P E T / C T ~ i m a g i n g ~ w a s ~ p e r f o r m e d . ~ T h e ~ r e s u l t s ~}$ showed that, in accordance with the results of in vitro ${ }^{18} \mathrm{~F}-\mathrm{FDG}$ uptake assay, after treatment with metformin, the SUVmax ratio of T/NT was much lower in group A compared to that in group B (Figs 5 and 6A).

\section{Decreased expression of GLUT1 and HK2 in vivo}

After microPET/CT scan, mice were killed, and the expression of HK2 and GLUT1 was detected by

Published by Bioscientifica Ltd 
A

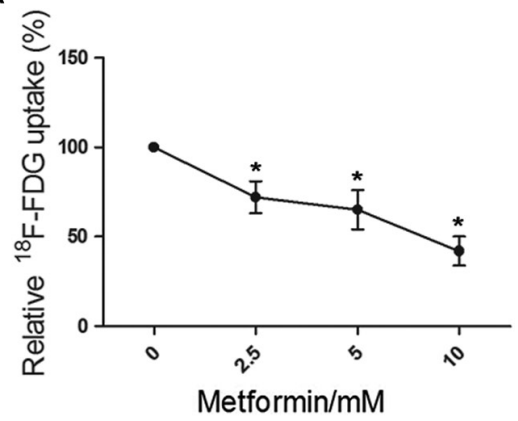

C

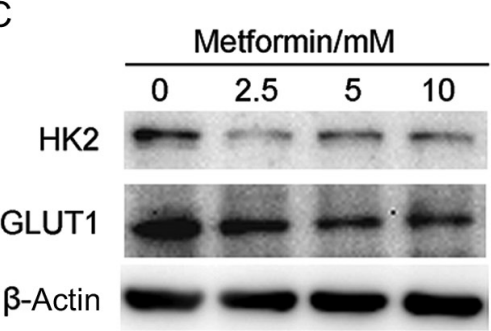

E

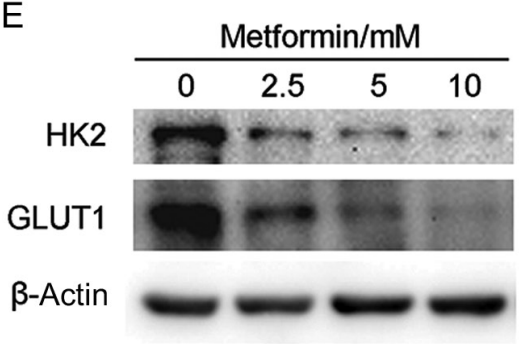

B
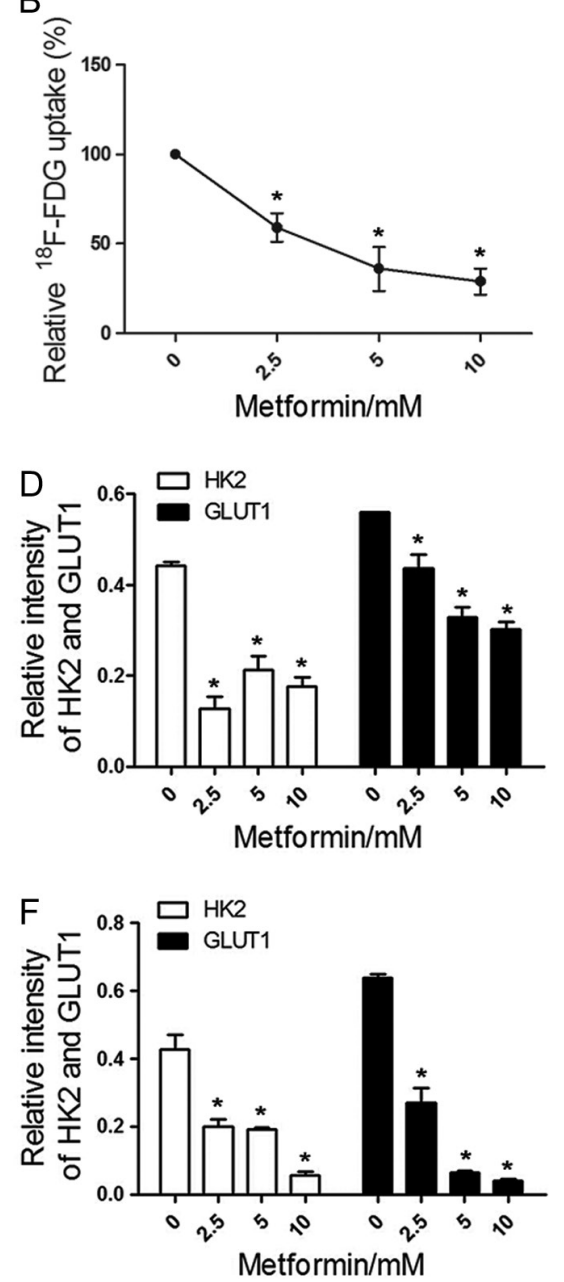

Figure 3

In vitro ${ }^{18} \mathrm{~F}-\mathrm{FDG}$ uptake assay and western blotting analysis of HK2 and GLUT1 in metformintreated cells at different concentrations. (A) and (C), KTC1; (B) and (E), BCPAP; (D) and (F), semi-quantitative analysis of blots in $(C)$ and $(E)$, respectively. ${ }^{*} P<0.05$. immunohistochemistry. Brown staining was located in the cytoplasm and membrane of BCPAP cell. The intensity of staining was much lower in metformin-treated group compared to that in non-metformin-treated group. These results indicated that the expression of HK2 and GLUT1 was decreased after metformin treatment in vivo (Figs 7 and 6B).

\section{Discussion}

In the current study, we found that metformin, as the most widely prescribed oral hypoglycemic agent in T2DM patients, could downregulate the expression of GLUT1 and HK2, thus decreasing the rate of glucose metabolism in papillary thyroid carcinoma in vitro and in vivo.

The anticancer effects of metformin have been widely sutdied recently, whereas the underlying mechanism is still not clearly illuminated. Mainly, the potential mechanisms involved are divided into two ways: 'direct effect' and 'indirect effect'
(Koritzinsky 2015, Luengo et al. 2014). The direct anticancer effects of metformin are found to be mainly mediated by AMPK-dependent way as well as AMPKindependent process. For AMPK-dependent way, studies have demonstrated that metformin's primary cellular targets are the mitochondrial complex I (Owen et al. 2000, Wheaton et al. 2014) and the mitochondrial glycerophosphate dehydrogenase (mGPD) enzyme (Madiraju et al. 2014). AMPK is activated due to the decrease of oxygen consumption and adenosine triphosphate (ATP) production, which results from the inhibition of complex I and consequently inhibition of the mitochondrial electron transport. This effect induces cell cycle arrest and inhibits protein synthesis in cancer cells (Hawley et al. 2010, Steinberg \& Kemp 2009). Cho and coworkers investigated the therapeutic potential of metformin in PTC, and their results indicated that metformin had anti-tumorigenic effects in PTC by activation of AMPK signaling and inhibition of AKT signaling (Cho et al. 2014a,b). However, other

Published by Bioscientifica Ltd 
A

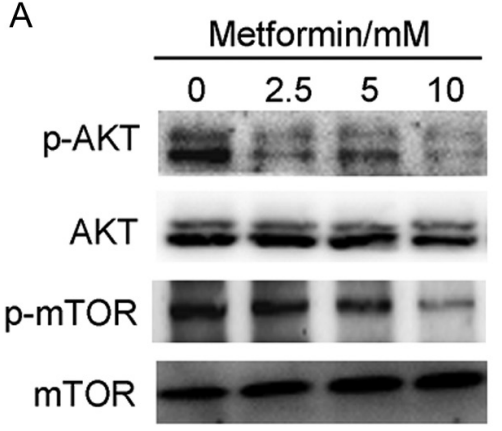

C

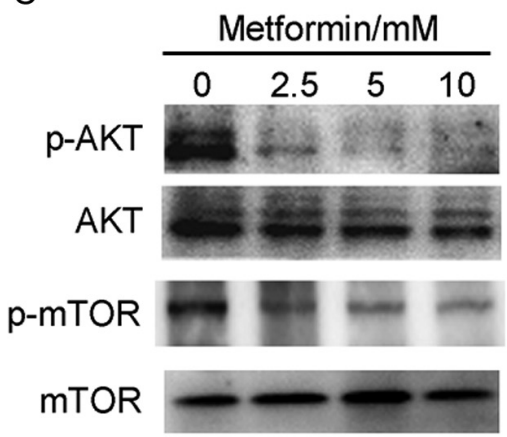

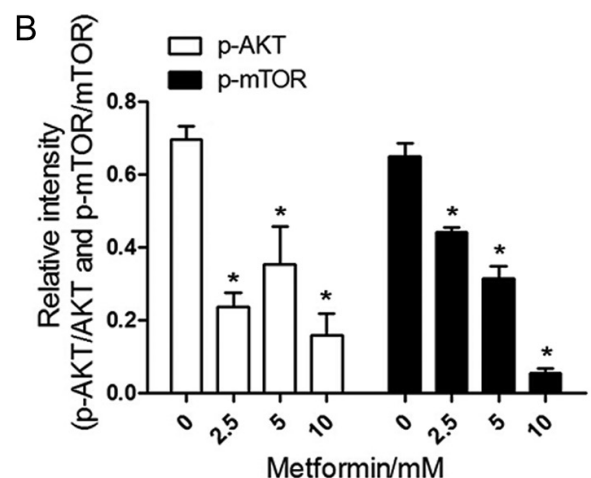

$\mathrm{D}$

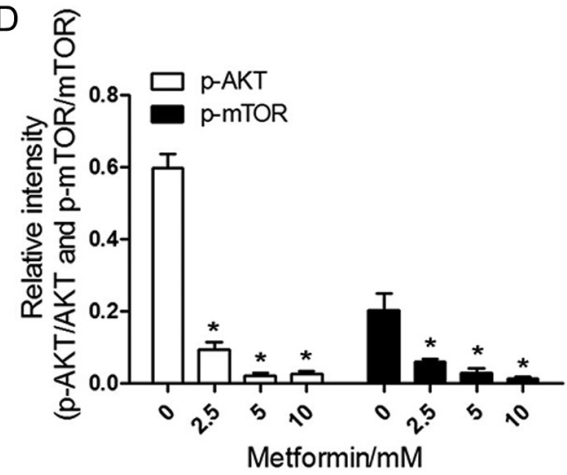

Figure 4

Western blotting analysis of AKT, p-AKT, mTOR and $\mathrm{p}$-mTOR in metformin-treated cells at different concentrations. (A) KTC1; (C) BCPAP;

(B) and (D), semi-quantitative analysis of blots in (A) and (C), respectively. ${ }^{*} P<0.05$. studies have reported that metformin could also regulate cancer cell biology in an AMPK-independent way through the inhibition of the unfolded protein response with a consequent apoptosis, preventing angiogenesis and exerting toxicity on cancer stem cells (Kourelis \& Siegel 2012). In addition, metforminreduced circulating levels of glucose, insulin and other factors that can stimulate tumor cells' proliferation is considered as its indirect effect (Algire et al. 2010, Sui et al. 2015).

Metabolic changes, known as the Warburg effect or aerobic glycolysis, have been discovered in the context of cancer diseases with the phenomenon that under aerobic conditions, proliferating cancer cells metabolize approximately tenfold more glucose to lactate in a given time than normal surrounding ones (Cairns et al. 2011,

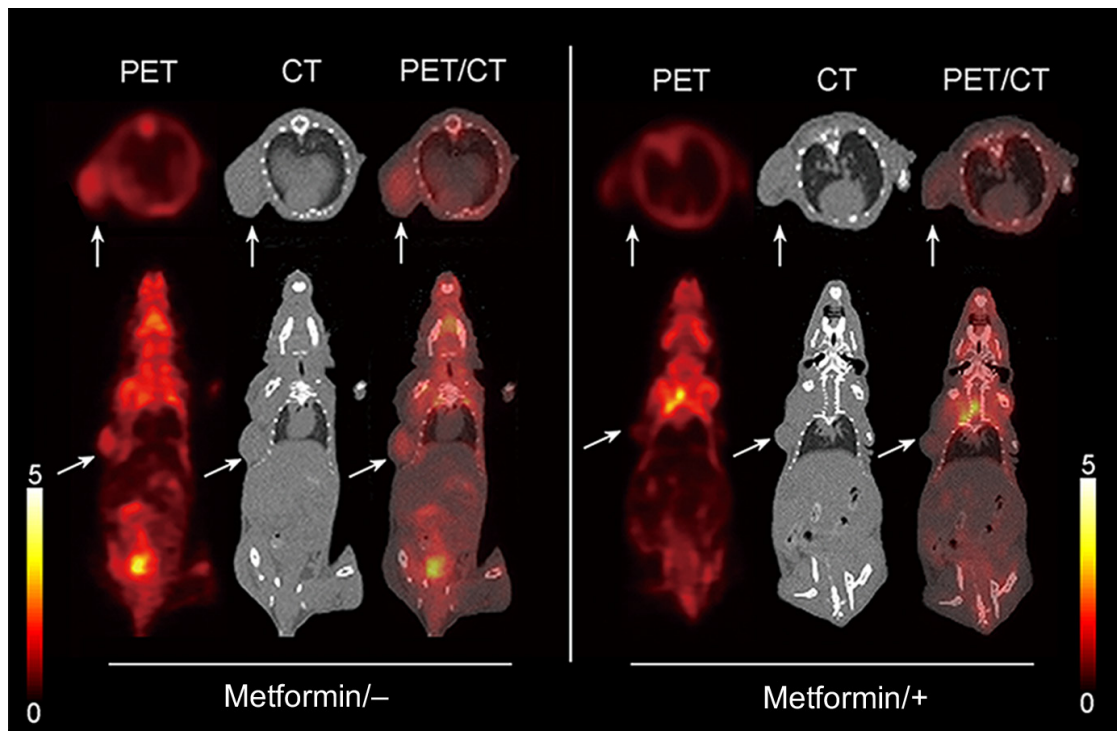

Figure 5

18F-FDG MicroPET/CT imaging in non-metformin-/ metformin-treated xenograft model of PTC. A full colour version of this figure is available at http:// dx.doi.org/10.1530/JME-16-0134. http://jme.endocrinology-journals.org
DOI: 10.1530/JME-16-0134
๑ 2017 Society for Endocrinology Printed in Great Britain
Published by Bioscientifica Ltd 
A

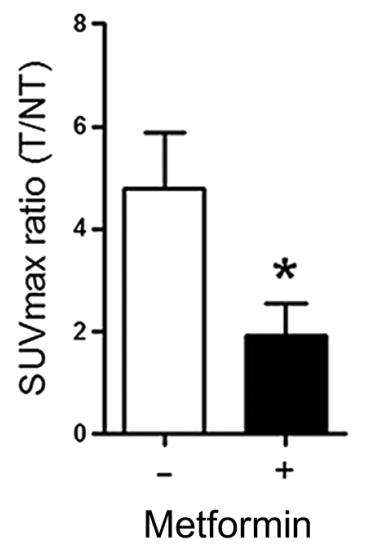

B

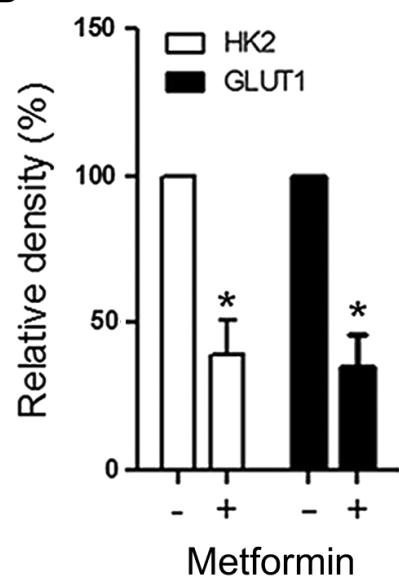

Figure 6

(A) SUVmax ratio (T/NT) comparison between non-metformin- and metformin-treated xenograft model of PTC in 18F-FDG MicroPET/CT imaging. (B) Semi-quantitative analysis of immunohistochemistry results. T, SUVmax of tumor; NT, SUVmax of nontarget reference (liver). ${ }^{\star} P<0.05$.

Koppenol et al. 2011). Recently, AMPK activation is found to have the ability to negatively regulate aerobic glycolysis (the Warburg effect) in cancer cells and suppress tumor growth (Faubert et al. 2013). Therefore, based on the fact that metformin is an activator of AMPK, another important role of metformin that could be involved in its anticancer activities is its capability to modulate the tumor cell metabolism.

Studies have showed that metformin could directly inhibit the enzymatic function of HK2 in different cancer models comprising Calu-1 cells as a model of non-smallcell lung cancer and in MDA-MB231 as a model of triplenegative breast cancer (Marini et al. 2013, Salani et al. 2013). In all these cells, metformin determined a

dose- and time-dependent reduction in ${ }^{18} \mathrm{~F}-\mathrm{FDG}$ uptake. However, Habibollahi et al. (2013) demonstrated that metformin, through activation of the AMPK pathway, exerted a dose-dependent increase in tumor glucose uptake in colon cancer cell lines HT29 (human) and MC26 (murine). In the current study, we examined the effect of metformin on the glucose metabolism in PTC cell lines, and the results demonstrated that metformin could decrease the ${ }^{18} \mathrm{~F}-\mathrm{FDG}$ uptake in BCPAP and KTC1 cells. To the best of our knowledge, this is the first study that tried to elucidate the anticancer effect of metformin under a cellular metabolism way in thyroid carcinoma. Although reduction of GLUT1 and HK2, activation of AMPK and inhibition of AKT/mTOR signaling could be of great importance during this process, the exact underlying mechanism of how activation of AMPK could regulate the expression of key enzymes of glycolytic pathway including glucose transporters and hexokinases in thyroid cancer cells is still not clearly known. This is the major limitation of our current work and intensive studies should be performed to further clarify the potential mechanism.

In conclusion, our results demonstrated that after treatment with metformin, PTC cells showed a dosedependent reduction of ${ }^{18} \mathrm{~F}-\mathrm{FDG}$ uptake both in vitro and in vivo in accordance with the downregulated expression of key enzymes in glycolytic pathway including GLUT1 and HK2. Activation of AMPK and inhibition of AKT/mTOR signaling by metformin might play an essential role in the process of this effect. Based on these findings, metformin by targeting glucose metabolism of cancer cell could be a promising adjuvant therapy alternative in the treatment modality of advanced thyroid carcinoma.
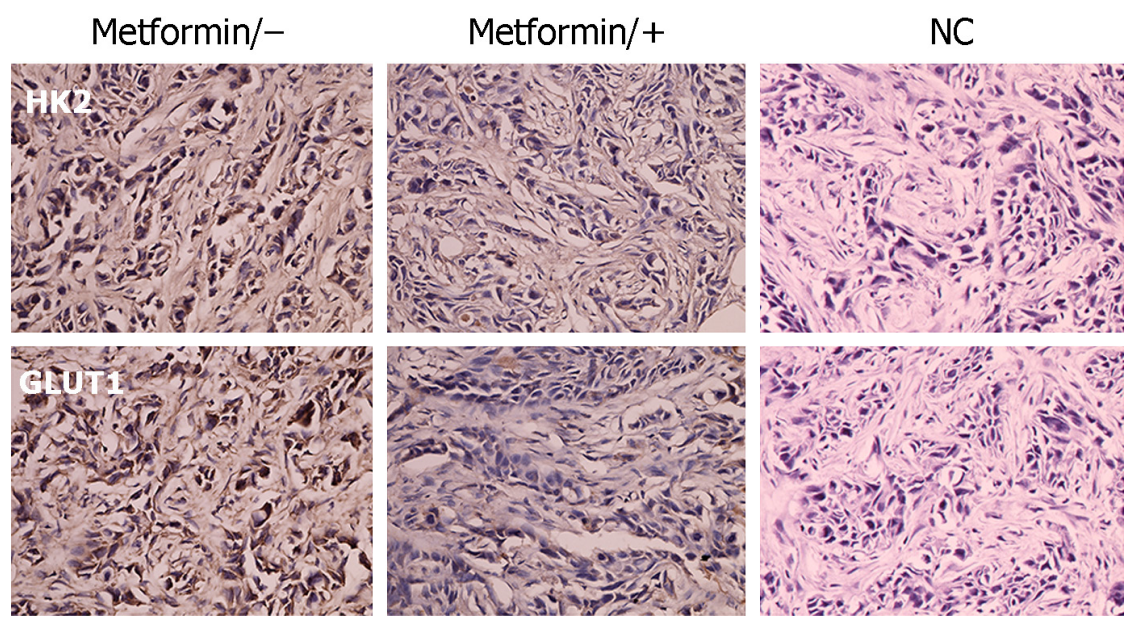

Figure 7

Immunohistochemistry analysis of HK2 and GLUT1 expression in non-metformin- and metformintreated PTC xenograft tissues. NC, negative control. A full colour version of this figure is available at http://dx.doi.org/10.1530/JME-16-0134. http://jme.endocrinology-journals.org DOI: 10.1530/JME-16-0134
(C) 2017 Society for Endocrinology Printed in Great Britain
Published by Bioscientifica Ltd. 


\section{Declaration of interest}

The authors declare that there is no conflict of interest that could be perceived as prejudicing the impartiality of the research reported.

\section{Funding}

This study was supported by the Doctorial Innovation Funding of Shanghai Jiao Tong University School of Medicine (No. BXJ201635) and the National Natural Science Foundation of China (No. 81271611).

\section{Author contribution statement}

Luo designed the study. Shen and Wei performed the experiments. Shen, Wei, Qiu and Song analyzed and interpreted the data. Shen wrote the manuscript. Luo, Sun and Zhang revised the manuscript. All authors read and approved the final manuscript.

\section{Acknowledgements}

The authors would like to thank Dr C Wang and Dr Q Liu (Renji Hospital, School of Medicine, Shanghai Jiao Tong University) for their help with the in vivo ${ }^{18} \mathrm{~F}-\mathrm{FDG}$ MicroPET/CT imaging.

\section{References}

Algire C, Amrein L, Zakikhani M, Panasci L \& Pollak M 2010 Metformin blocks the stimulative effect of a high-energy diet on colon carcinoma growth in vivo and is associated with reduced expression of fatty acid synthase. Endocrine-Related Cancer 17 351-360. (doi:10.1677/ERC-09-0252)

Becker C, Jick SS, Meier CR \& Bodmer M 2015 No evidence for a decreased risk of thyroid cancer in association with use of metformin or other antidiabetic drugs: a case-control study. BMC Cancer 15 719. (doi:10.1186/s12885-015-1719-6)

Cairns RA, Harris IS \& Mak TW 2011 Regulation of cancer cell metabolism. Nature Reviews Cancer 11 85-95. (doi:10.1038/nrc2981)

Chen G, Xu S, Renko K \& Derwahl M 2012 Metformin inhibits growth of thyroid carcinoma cells, suppresses self-renewal of derived cancer stem cells, and potentiates the effect of chemotherapeutic agents. Journal of Clinical Endocrinology and Metabolism 97 E510-E520. (doi:10.1210/jc.2011-1754)

Chen W, Zheng R, Baade PD, Zhang S, Zeng H, Bray F, Jemal A, Yu XQ \& He J 2016 Cancer statistics in China, 2015. CA: A Cancer Journal for Clinicians 66 115-132. (doi:10.1017/S0009840X15002048)

Cho SW, Yi KH, Han SK, Sun HJ, Kim YA, Oh BC, Park YJ \& Park DJ $2014 a$ Therapeutic potential of metformin in papillary thyroid cancer in vitro and in vivo. Molecular and Cellular Endocrinology 393 24-29. (doi:10.1016/j.mce.2014.05.021)

Cho SW, Yi KH, Han SK, Sun HJ, Kim YA, Oh BC, Park YJ \& Park do J $2014 b$ Therapeutic potential of metformin in papillary thyroid cancer in vitro and in vivo. Molecular and Cellular Endocrinology 393 24-29. (doi:10.1016/j.mce.2014.05.021)

Colell A, Ricci JE, Tait S, Milasta S, Maurer U, Bouchier-Hayes L, Fitzgerald P, Guio-Carrion A, Waterhouse NJ, Li CW, et al. 2007 GAPDH and autophagy preserve survival after apoptotic cytochrome c release in the absence of caspase activation. Cell 129 983-997. (doi:10.1016/j.cell.2007.03.045)

Crandall JP, Knowler WC, Kahn SE, Marrero D, Florez JC, Bray GA, Haffner SM, Hoskin M \& Nathan DM 2008 The prevention of type 2 diabetes. Nature Clinical Practice Endocrinology and Metabolism 4 382-393. (doi:10.1038/ncpendmet0843)
Faubert B, Boily G, Izreig S, Griss T, Samborska B, Dong Z, Dupuy F, Chambers C, Fuerth BJ, Viollet B, et al. 2013 AMPK is a negative regulator of the Warburg effect and suppresses tumor growth in vivo. Cell Metabolism 17 113-124. (doi:10.1016/j.cmet.2012.12.001)

Gandini S, Puntoni M, Heckman-Stoddard BM, Dunn BK, Ford L, DeCensi A \& Szabo E 2014 Metformin and cancer risk and mortality: a systematic review and meta-analysis taking into account biases and confounders. Cancer Prevention Research 7 867-885. (doi:10.1158/1940-6207.CAPR-13-0424)

Habibollahi P, van den Berg NS, Kuruppu D, Loda M \& Mahmood U 2013 Metformin - an adjunct antineoplastic therapy - divergently modulates tumor metabolism and proliferation, interfering with early response prediction by 18F-FDG PET imaging. Journal of Nuclear Medicine 54 252-258. (doi:10.2967/jnumed.112.107011)

Hanly EK, Bednarczyk RB, Tuli NY, Moscatello AL, Halicka HD, Li J, Geliebter J, Darzynkiewicz Z \& Tiwari RK 2015 mTOR inhibitors sensitize thyroid cancer cells to cytotoxic effect of vemurafenib. Oncotarget 6 39702-39713. (doi:10.18632/oncotarget.4052)

Hawley SA, Ross FA, Chevtzoff C, Green KA, Evans A, Fogarty S, Towler MC, Brown LJ, Ogunbayo OA, Evans AM, et al. 2010 Use of cells expressing gamma subunit variants to identify diverse mechanisms of AMPK activation. Cell Metabolism 11 554-565. (doi:10.1016/j.cmet.2010.04.001)

Klubo-Gwiezdzinska J, Costello J Jr, Patel A, Bauer A, Jensen K, Mete M, Burman KD, Wartofsky L \& Vasko V 2013 Treatment with metformin is associated with higher remission rate in diabetic patients with thyroid cancer. Journal of Clinical Endocrinology and Metabolism 98 3269-3279. (doi:10.1210/jc.2012-3799)

Koppenol WH, Bounds PL \& Dang CV 2011 Otto Warburg's contributions to current concepts of cancer metabolism. Nature Reviews Cancer 11 325-337. (doi:10.1038/nrc3038)

Koritzinsky M 2015 Metformin: a novel biological modifier of tumor response to radiation therapy. International Journal of Radiation Oncology, Biology, Physics 93 454-464. (doi:10.1016/j. ijrobp.2015.06.003)

Kourelis TV \& Siegel RD 2012 Metformin and cancer: new applications for an old drug. Medical Oncology 29 1314-1327. (doi:10.1007/ s12032-011-9846-7)

Luengo A, Sullivan LB \& Heiden MG 2014 Understanding the complexI-ty of metformin action: limiting mitochondrial respiration to improve cancer therapy. BMC Biology 12 82. (doi:10.1186/s12915014-0082-4)

Madiraju AK, Erion DM, Rahimi Y, Zhang XM, Braddock DT, Albright RA, Prigaro BJ, Wood JL, Bhanot S, MacDonald MJ, et al. 2014 Metformin suppresses gluconeogenesis by inhibiting mitochondrial glycerophosphate dehydrogenase. Nature $\mathbf{5 1 0}$ 542-546. (doi:10.1038/nature13270)

Marini C, Salani B, Massollo M, Amaro A, Esposito AI, Orengo AM, Capitanio S, Emionite L, Riondato M, Bottoni G, et al. 2013 Direct inhibition of hexokinase activity by metformin at least partially impairs glucose metabolism and tumor growth in experimental breast cancer. Cell Cycle 12 3490-3499. (doi:10.4161/cc.26461)

Masson-Deshayes S, Schvartz C, Dalban C, Guendouzen S, Pochart JM, Dalac A, Fieffe S, Bruna-Muraille C, Dabakuyo-Yonli TS \& Papathanassiou D 2015 Prognostic value of (18)F-FDG PET/CT metabolic parameters in metastatic differentiated thyroid cancers. Clinical Nuclear Medicine 40 469-475. (doi:10.1097/ RLU.0000000000000780)

Mondal S, Roy D, Camacho-Pereira J, Khurana A, Chini E, Yang L, Baddour J, Stilles K, Padmabandu S, Leung S, et al. 2015 HSulf-1 deficiency dictates a metabolic reprograming of glycolysis and TCA cycle in ovarian cancer. Oncotarget 6 33705-33719. (doi:10.18632/ oncotarget.5605)

Owen MR, Doran E \& Halestrap AP 2000 Evidence that metformin exerts its anti-diabetic effects through inhibition of complex 1 of the 
mitochondrial respiratory chain. Biochemical Journal 348 607-614. (doi:10.1042/bj3480607)

Pollak MN 2012 Investigating metformin for cancer prevention and treatment: the end of the beginning. Cancer Discovery 2 778-790. (doi:10.1158/2159-8290.CD-12-0263)

Pryma DA, Schoder H, Gonen M, Robbins RJ, Larson SM \& Yeung HW 2006 Diagnostic accuracy and prognostic value of 18F-FDG PET in Hurthle cell thyroid cancer patients. Journal of Nuclear Medicine $\mathbf{4 7}$ 1260-1266.

Robey RB \& Hay N 2009 Is Akt the 'Warburg kinase'?-Akt-energy metabolism interactions and oncogenesis. Seminars in Cancer Biology 19 25-31. (doi:10.1016/j.semcancer.2008.11.010)

Salani B, Marini C, Rio AD, Ravera S, Massollo M, Orengo AM, Amaro A, Passalacqua M, Maffioli S, Pfeffer U, et al. 2013 Metformin impairs glucose consumption and survival in Calu-1 cells by direct inhibition of hexokinase-II. Scientific Reports 3 2070. (doi:10.1038/srep02070)

Salvatori M, Biondi B \& Rufini V 2015 Imaging in endocrinology: 2-[18F]-fluoro-2-deoxy-d-glucose positron emission tomography/ computed tomography in differentiated thyroid carcinoma: clinical indications and controversies in diagnosis and follow-up. European Journal of Endocrinology 173 R115-R130. (doi:10.1530/EJE-15-0066)

Schonberger J, Ruschoff J, Grimm D, Marienhagen J, Rummele P, Meyringer R, Kossmehl P, Hofstaedter F \& Eilles C 2002 Glucose transporter 1 gene expression is related to thyroid neoplasms with an unfavorable prognosis: an immunohistochemical study. Thyroid 12 747-754. (doi:10.1089/105072502760339307)

Siegel RL, Miller KD \& Jemal A 2016 Cancer statistics, 2016. CA: A Cancer Journal for Clinicians 66 7-30. (doi:10.1017/ S0009840X15002851)

Steinberg GR \& Kemp BE 2009 AMPK in health and disease. Physiological Reviews 89 1025-1078. (doi:10.1152/physrev.00011.2008)

Sui X, Xu Y, Wang X, Han W, Pan H \& Xiao M 2015 Metformin: a novel but controversial drug in cancer prevention and treatment. Molecular Pharmaceutics 12 3783-3791. (doi:10.1021/acs. molpharmaceut.5b00577)

Tseng CH 2014 Metformin reduces thyroid cancer risk in Taiwanese patients with type 2 diabetes. PLOS ONE 9 e109852. (doi:10.1371/ journal.pone.0109852)

Vander Heiden MG 2011 Targeting cancer metabolism: a therapeutic window opens. Nature Reviews Drug Discovery 10 671-684. (doi:10.1038/nrd3504)

Wheaton WW, Weinberg SE, Hamanaka RB, Soberanes S, Sullivan LB, Anso E, Glasauer A, Dufour E, Mutlu GM, Budigner GS, et al. 2014 Metformin inhibits mitochondrial complex I of cancer cells to reduce tumorigenesis. eLife 3 e02242. (doi:10.7554/ elife.02242)

Received in final form 31 October 2016

Accepted 6 November 2016 (c) 2017 Society for Endocrinology Printed in Great Britain
Published by Bioscientifica Ltd. 